\title{
Synthesis and Structural Characterization of
}

\section{Stoichiometric Li-Ga-Ge Sulfo-Selenide Glasses}

\author{
M.A.T. Marple ${ }^{a}$, B.G. Aitken ${ }^{b}$, S. Sen ${ }^{a}$,*
}




\begin{abstract}
Homogeneous glasses in the mixed-chalcogen pseudo-ternary system $\mathrm{Li}_{2} \mathrm{~S}-\mathrm{Ga}_{2} \mathrm{Se}_{3}-\mathrm{GeSe}_{2}$ are synthesized and their structure is characterized using Raman and one- and two-dimensional ${ }^{6} \mathrm{Li},{ }^{77} \mathrm{Se}$, and ${ }^{71} \mathrm{Ga}$ nuclear magnetic resonance (NMR) spectroscopy. The structure of these glasses can be described as a charge-compensated network predominantly consisting of corner sharing $(\mathrm{Ga} / \mathrm{Ge})(\mathrm{Se}, \mathrm{S})_{4 / 2}$ tetrahedra. The compositional evolution of the atomic structure is heavily influenced by the $\mathrm{Li}_{2} \mathrm{~S}: \mathrm{Ga}_{2} \mathrm{Se}_{3}$ ratio $\mathrm{R}$ where charge compensation is accommodated by the formation of different structural units and preferential chemical ordering for $\mathrm{S}$ atoms. Glasses with $\mathrm{R}<1$ are deficient in chalcogens required to satisfy the tetrahedral coordination of $\mathrm{Ga}$ and consequently form ethane-like $\mathrm{X}_{3} \mathrm{Ge}-\mathrm{GeX}_{3}(\mathrm{X}=\mathrm{S}, \mathrm{Se})$ units and $\mathrm{S}$ atoms preferentially participate in these structural units. On the other hand, the structure of chalcogen-excess glasses with $\mathrm{R}>1$ are characterized by the formation of non-bridging Se (NBSe) and S (NBS) sites. The Se atoms show a preference over $\mathrm{S}$ for these non-bridging sites and form Ge-NBSe linkages, while the $\mathrm{S}$ atoms preferentially bond to $\mathrm{Ga}$, resulting in the formation of $\mathrm{GaS}_{4 / 2}$ tetrahedra. This structural scenario is shown to be consistent with the corresponding changes in the glass transition temperature.
\end{abstract}




\section{Introduction}

Chalcogenide glasses, owing to their unique optical and semiconducting properties, have found wide ranging applications in the areas of telecommunication, remote sensing, energy and memory storage [1-3]. Compared to oxide glasses, the compositional flexibility of chalcogenides allows for excellent tuning of their electronic and optical properties. However, the majority of studies in the literature have focused on the structure-property relationships in Ge-As-P-X (X=S, $\mathrm{Se}, \mathrm{Te}$ ) glasses that are characterized by fully connected covalent networks that follow the 8-N bonding rule [4-8]. In comparison, relatively little is known about chalcogenide glasses with modified networks [9-11].

Chalcogenide networks modified with alkali and/or alkaline-earth sulfides or selenides are prone to devitrification and phase separation. Addition of glass forming intermediates such as Ga can often alleviate these shortcomings $[12,13]$ via creation of a compensated network that allows for homogeneous incorporation of high concentration of modifiers. The modifier cations charge balance the $\left[\mathrm{Ga}(\mathrm{S} / \mathrm{Se})_{4 / 2}\right]^{-}$tetrahedra in the structure. In fact, it is possible to synthesize pseudo-ternary glasses in the stoichiometric system $\mathrm{M}_{2} \mathrm{X} / \mathrm{M}^{\prime} \mathrm{X}-\mathrm{Ga}_{2} \mathrm{X}_{3}-\mathrm{GeX}_{2} \quad\left[\mathrm{M}=\right.$ alkali; $\mathrm{M}^{\prime}=$ alkaline-earth] that are isoelectronic analogues of alkali/alkaline-earth aluminosilicate glasses with partially or fully compensated network. Recent works on $\mathrm{Ag}_{2} \mathrm{Se} / \mathrm{Na}_{2} \mathrm{Se} / \mathrm{BaSe}-\mathrm{Ga}_{2} \mathrm{Se}_{3}$ $\mathrm{GeSe}_{2}$ glasses have shown that the ratio of modifier to intermediate content $\mathrm{R}=\mathrm{M}_{2} \mathrm{X} / \mathrm{M}^{\prime} \mathrm{X}: \mathrm{Ga}_{2} \mathrm{X}_{3}$ is of critical importance in controlling the structural evolution of the network in these compensated chalcogenide glasses [14-16]. In the case of $\mathrm{R}<1$, these glasses are considered to be chalcogen deficient for satisfying the tetrahedral coordination of heteropolar bonded Ga and Ge atoms and this deficiency is accommodated in the structure primarily via the formation of Ge-Ge homopolar bonds. On the other hand, for $\mathrm{R}>1$ the glasses contain an excess of 
chalcogen which results in the formation of non-bridging S/Se (NBS/NBSe), similar to the formation of non-bridging oxygen (NBO) in modifier-excess oxide glasses. As continuation of our efforts to understand the structure-property relationships of chalcogenide glasses with compensated networks, we have investigated glasses in the system $\mathrm{Li}_{2} \mathrm{~S}-\mathrm{Ga}_{2} \mathrm{Se}_{3}-\mathrm{GeSe}_{2}$ (LGGS/Se). Sulfur is incorporated in these glasses, in addition to selenium, in order to probe how the structure of these compensated networks, containing mixed chalcogen atoms with different electronegativities and therefore, with different degrees of ionicity of the constituent heteropolar bonds is influenced by the variation in R. In the present study, we report the results of an investigation into glass formation and structural characteristics of glasses in the LGGS/Se system, using Raman and multi-nuclear $\left({ }^{6} \mathrm{Li},{ }^{77} \mathrm{Se}\right.$, and $\left.{ }^{71} \mathrm{Ga}\right)$ magnetic resonance (NMR) spectroscopy. The compositional evolution of the atomic structure of these glasses is then linked to corresponding variation in the glass transition temperature $\mathrm{T}_{\mathrm{g}}$.

\section{Experimental Methods}

\subsection{Glass Synthesis}

All glasses were prepared by a melt-quench method. The compositions were batched within a nitrogen atmosphere glovebox with the $\mathrm{H}_{2} \mathrm{O}$ and $\mathrm{O}_{2}$ levels less than $0.1 \mathrm{ppm}$. A twostep melting procedure was used in order to minimize possible reaction of $\mathrm{Li}$ with the walls of the fused quartz ampoules. Approximately $25 \mathrm{~g}$ batches of precursor Ga-Ge-Se alloys were prepared for each composition by melting mixtures containing appropriate amounts of constituent elements $\mathrm{Se}, \mathrm{Ga}$ and Ge (99.9999\% purity) in sealed fused quartz ampoules evacuated to $8^{*} 10^{-5}$ torr. The mixtures were melted in a rocking furnace for three days at $950^{\circ} \mathrm{C}$ 
and subsequently quenched in water. The material was extracted from the ampoule and crushed into powder. Approximately $10 \mathrm{~g}$ batches of glass were made by mixing appropriate amounts of $\mathrm{Li}_{2} \mathrm{~S}(99.99 \%$ purity) and precursor Ga-Ge-Se alloy powder and melting the mixtures in silicon coated fused quartz ampoules. The ampoules were sealed under vacuum at $8^{*} 10^{-5}$ torr and loaded into a vertical furnace at $950^{\circ} \mathrm{C}$. After 15 minutes of melting, the ampoules were removed and tilted to homogenize the liquid and then loaded back into the furnace to melt for another 15 minutes. The ampoules were subsequently quenched in water and annealed in a furnace at $200^{\circ} \mathrm{C}$ for 30 minutes. The glasses were extracted from the ampoules within an Ar glovebox as the Li rich compositions are extremely hygroscopic and react within less than 30 minutes of exposure to ambient air. The Ga rich compositions display better stability to ambient air and showed no signs of degradation while being stored in a desiccator for more than a week. The possible devitrification of the samples was checked with powder $\mathrm{x}$-ray diffraction. The $\mathrm{T}_{\mathrm{g}}$ of the X-ray amorphous samples was determined using differential scanning caloriemetry (DSC). Conventional DSC scans were taken using a Mettler-Toledo DSC1 calorimeter. Scans were performed in a flowing nitrogen environment on 15-20 mg of sample loaded into $40 \mu \mathrm{L}$ aluminum crucibles. The glass transition temperature $T_{g}$ is determined as the onset of the glass transition region, when heating at a rate of $20 \mathrm{~K} / \mathrm{min}$.

\subsection{Raman Spectroscopy}

Raman spectra of the glasses were collected on a Bruker RFS 100/S Fourier-transform (FT) Raman spectrometer equipped with a Nd:YAG laser operating at an excitation wavelength of $1064 \mathrm{~nm}$. Glass powder was packed into a sample holder and covered with clear tape to prevent contamination with moisture. Each spectrum is the average of 128 scans collected in backscattering geometry at room temperature using a power level of $30 \mathrm{~mW}$ and a resolution of 2 
$\mathrm{cm}^{-1}$ resolution. Additionally, Raman spectra were collected as a function of time after removing the tape to monitor spectral changes resulting from the interaction of the sample with ambient moisture.

\subsection{NMR Spectroscopy}

\subsubsection{Measurements at low magnetic field (11.7 T)}

The NMR spectra at $11.7 \mathrm{~T}$ were collected using a Bruker Avance500 spectrometer operating at resonance frequencies of 73.6, 95.4, and $152.5 \mathrm{MHz}$ for ${ }^{6} \mathrm{Li},{ }^{77} \mathrm{Se}$ and ${ }^{71} \mathrm{Ga}$, respectively. The glass samples were crushed into powder and packed into $4 \mathrm{~mm}$ or $5 \mathrm{~mm} \mathrm{ZrO}_{2}$ or $\mathrm{Si}_{3} \mathrm{~N}_{4}$ rotors. Due to the hygroscopic nature of the samples, all packing was carried out in an Arfilled glovebox to avoid any exposure to moisture. The one-pulse ${ }^{6} \mathrm{Li}$ NMR spectra were collected using a Bruker triple-resonance magic-angle-spinning (MAS) probe, a $\pi / 4$ pulse $(2.25$ $\mu \mathrm{s})$ and a recycle delay of $10 \mathrm{~s}$. Samples were spun at $12 \mathrm{kHz}$ and 16 free induction decays (FID) were averaged and Fourier transformed to obtain each spectrum. The ${ }^{77}$ Se MAS NMR spectra were collected using a Doty MAS probe. Samples were taken in a $5 \mathrm{~mm} \mathrm{Si}_{3} \mathrm{~N}_{4}$ rotor and

spun at $\sim 14 \mathrm{kHz}$. A Hahn echo pulse sequence was used with a rotor synchronized delay between the $\pi / 2(2.2 \mu \mathrm{s})$ and $\pi(4.4 \mu \mathrm{s})$ pulses and a recycle delay of $120 \mathrm{~s}$. At least 512 FIDs were averaged and the entire echo was Fourier transformed to obtain each spectrum. The ${ }^{71} \mathrm{Ga}$ NMR spectra were obtained using the two-dimensional (2D) quadrupolar magic angle turning (QMAT) experiment as reported in the literature [17]. The QMAT pulse sequence uses nine central transition selective pulses with linearly varied delays to produce a MAS spectrum free of sidebands. Crushed glass was packed in a $4 \mathrm{~mm} \mathrm{ZrO}_{2}$ rotor and was spun at $10 \mathrm{kHz}$. For each QMAT experiment $16 t_{1}$ increments were employed over the rotor period with 10000 transients 
per $t_{1}$ increment and a recycle delay of $0.2 \mathrm{~s}$ between each transient. The central transition selective $\pi / 2$ and $\pi$ pulse lengths were 1.2 and $2.4 \mu$ s, respectively. After data collection, the $16 t_{1}$ increments are sheared and summed together, then Fourier transformed in the direct and indirect dimensions to produce an "infinite" spinning speed ${ }^{71} \mathrm{Ga}$ MAS spectrum. The ${ }^{6} \mathrm{Li},{ }^{77} \mathrm{Se}$, and ${ }^{71} \mathrm{Ga}$ chemical shifts were externally referenced to the isotropic chemical shift $\delta_{\text {iso }}$ of solid $\mathrm{LiCl}\left(\delta_{\text {iso }}=0\right.$ ppm), crystalline $\left(\mathrm{NH}_{4}\right)_{2} \mathrm{SeO}_{4}\left(\delta_{\text {iso }}=1040.2 \mathrm{ppm}\right)$, and $1 \mathrm{M}$ aqueous solution of $\mathrm{Ga}\left(\mathrm{NO}_{3}\right)_{3}\left(\delta_{\text {iso }}=0\right.$ ppm), respectively.

\subsubsection{Measurements at high magnetic field (19.6 T)}

Two-dimensional (2D) ${ }^{77} \mathrm{Se}$ magic angle turning phase adjusted sideband separation (MATPASS) spectra were collected at the field of $19.6 \mathrm{~T}$ at the National High Magnetic Field Laboratory using an ultra-narrow bore magnet equipped with a Bruker DRX console operating at

a resonance frequency of $158.8 \mathrm{MHz}$ for ${ }^{77} \mathrm{Se}$. The crushed glass sample was packed into a 3.2 $\mathrm{mm} \mathrm{ZrO}_{2}$ rotor and spun at $10 \mathrm{kHz}$. High-resolution $2 \mathrm{D}{ }^{77} \mathrm{Se}$ MATPASS data were collected with Carr-Purcell-Meiboom-Gill (CPMG) echo-train acquisition to enhance sensitivity. The MATPASS experiment separates the isotropic chemical shift from chemical shift anisotropy (CSA) into two dimensions. The MATPASS/CPMG pulse sequence uses a series of five MAT $\pi$ pulses $(4.4 \mu \mathrm{s})$ with incremented inter-pulse delays according to the timings detailed by Hung et al. [18]. The experiment acquired 16 hypercomplex $t_{1}$ points with 36 transients per point and 32 CPMG echoes per transient with a recycle delay of 60 s. Hypercomplex data acquisition was employed using the method of States et al. to the phases of the CPMG pulses and the receiver [19]. 
Following the Haeberlen convention the principle components of the chemical shift tensor $\left(\delta_{\mathrm{xx}}, \delta_{\mathrm{yy}}\right.$, and $\left.\delta_{\mathrm{zz}}\right)$ are expressed in terms of the isotropic chemical shift $\delta_{\text {iso, }}$, the magnitude of anisotropy $\Delta$, and the asymmetry parameter $\eta$. These terms are defined as:

$\delta_{i s o}=\frac{1}{3}\left(\delta_{z z}+\delta_{y y}+\delta_{x x}\right) ; \Delta=\delta_{z z}-\delta_{i s o} ; \eta=\frac{\delta_{x x}-\delta_{y y}}{\Delta}$

where, $\delta_{z z}-\delta_{i s o} \geq \delta_{x x}-\delta_{i s o} \geq \delta_{y y}-\delta_{i s o}$ [20]. All simulations of the NMR spectra were performed using the Dmfit software package [21].

\section{Results}

\subsection{Glass Formation Range}

The composition range for glass formation for the pseudo-ternary system LGGS/Se is shown in Fig. 1. The circles mark compositions that are x-ray amorphous and have a clear signature of glass transition in their DSC trace. It is immediately obvious that the glass formation region in this system is quite limited with only compositions rich in $\mathrm{Li}_{2} \mathrm{~S}(\mathrm{R}>1)$ or rich in $\mathrm{Ga}_{2} \mathrm{Se}_{3}$

$(\mathrm{R}<1)$ forming homogeneous glasses. The compositions near $\mathrm{R}=1$ show various degrees of crystallinity in the $\mathrm{x}$-ray powder patterns forming a region of devitrification along the center of the pseudo-ternary diagram. Glasses in this composition region are prone to devitrification upon cooling, forming the stable crystalline phase $\mathrm{LiGaGe}_{2} \mathrm{Se}_{6}$. Similar glass formation regions have also been reported for other alkali and alkaline-earth containing $\mathrm{Ga}_{2} \mathrm{X}_{3}-\mathrm{GeX}_{2}(\mathrm{X}=\mathrm{S}, \mathrm{Se})$ glasses $[14,22-24]$ with analogous crystalline compounds forming upon devitrification for compositions nearing $\mathrm{R}=1$. It is interesting to note the glass formation region along the $\mathrm{Li}_{2} \mathrm{~S}+\mathrm{GeSe}_{2}$ join resembles that of the $\mathrm{Li}_{2} \mathrm{Se}+\mathrm{GeSe}_{2}$ join where glass formation is observed only for $40 \% \mathrm{Li}_{2} \mathrm{Se}$ 
using conventional water quenching [9]. The analogous sulfide system, on the other hand, can form glasses for compositions extending from 0 to $50 \% \mathrm{Li}_{2} \mathrm{~S}$ [10] . The color of the LGGS/Se glasses synthesized in the present study varies from deep red for $\mathrm{Ga}_{2} \mathrm{Se}_{3}$ rich compositions to a lighter red for the $\mathrm{Li}_{2} \mathrm{~S}$ rich compositions reflecting a narrowing of the optical band gap with increasing amount of Se relative to $\mathrm{S}$.

\subsection{Glass Transition Temperature}

The glass transition temperatures for all homogeneous LGGS/Se glasses synthesized in this study are listed in Table 1. Overall there is relatively little change in the glass transition temperature within each of the regions with $\mathrm{R}>1$ or, with $\mathrm{R}<1$. The glasses with $\mathrm{R}>1$ are characterized by $\mathrm{T}_{\mathrm{g}}$ in the range $\sim 290^{\circ} \mathrm{C}-304^{\circ} \mathrm{C}$ with a monotonic decrease in $\mathrm{T}_{\mathrm{g}}$ as $\mathrm{GeSe}_{2}$ is replaced with $\mathrm{Li}_{2} \mathrm{~S}$. Comparison between glasses with $40 \mathrm{~mol} \% \mathrm{Li}_{2} \mathrm{~S}$, with or without $\mathrm{Ga}$ indicates an increase in $\mathrm{T}_{\mathrm{g}}$ by $\sim 10^{\circ} \mathrm{C}$ with the substitution of $10 \mathrm{~mol} \% \mathrm{Ga}_{2} \mathrm{Se}_{3}$ for $\mathrm{GeSe}_{2}$. The $\mathrm{R}<1$ glasses are characterized by $\mathrm{T}_{\mathrm{g}}$ ranging between $\sim 360^{\circ} \mathrm{C}-376^{\circ} \mathrm{C}$ and there is a monotonic increase in $T_{g}$ with decreasing $\mathrm{GeSe}_{2}$ content. The relatively large difference between the $\mathrm{T}_{\mathrm{g}}$ values of glasses with $R>1$ and those with $R<1$, suggests a correspondingly significant difference between them in their network structure and bonding characteristics.

\subsection{Raman Spectroscopy}

The Raman spectra of all LGGS/Se glasses synthesized in this study are shown in Fig. 2. Spectral features for these glasses extend from $\sim 50 \mathrm{~cm}^{-1}$ to $\sim 450 \mathrm{~cm}^{-1}$. The spectral region between 50 and $150 \mathrm{~cm}^{-1}$ is characterized by relatively broad bands associated with the various symmetric and asymmetric bending modes of corner-shared $\mathrm{GeS}_{n} \mathrm{Se}_{4-\mathrm{n}}$ tetrahedra. This spectral region remains relatively invariant with composition for glasses with $\mathrm{R}<1$ (Fig. 2a). With 
increasing Li content, the glasses with $\mathrm{R}>1$ (Fig. 2b) show an increase in intensity of the $v_{2}$ and $v_{4}$ modes of the $\mathrm{GeS}_{\mathrm{n}} \mathrm{Se}_{4-\mathrm{n}}$ tetrahedra near 110 and $150 \mathrm{~cm}^{-1}$, respectively [25]. A relatively sharp peak at $86 \mathrm{~cm}^{-1}$ is distinguishable in all Raman spectra, which originates from the Al-alloy sample holder used in these experiments.

The spectral region between 150 and $270 \mathrm{~cm}^{-1}$ in all glasses is dominated by a compositionally invariant band at $200 \mathrm{~cm}^{-1}$ corresponding to the symmetric breathing mode of the corner sharing $(\mathrm{Ge} / \mathrm{Ga}) \mathrm{Se}_{4 / 2}$ tetrahedra. Within this spectral region, the $\mathrm{Ga}_{2} \mathrm{Se}_{3}$ rich glasses with $\mathrm{R}<1$ (Fig. 2a) display bands at 175 and $215 \mathrm{~cm}^{-1}$ that can be readily assigned to the stretching of homopolar Ge-Ge bonds in ethane-like $\left(\mathrm{Se}_{3}\right) \mathrm{Ge}-\mathrm{Ge}\left(\mathrm{Se}_{3}\right)$ units and to the breathing mode of edge sharing $\mathrm{GeSe}_{4 / 2}$ tetrahedra, respectively. These features are most prominent in the Raman spectrum of the glass with the lowest modifier $\left(\mathrm{Li}_{2} \mathrm{~S}\right)$ content and strongly resemble the Raman spectra of binary $\mathrm{Ga}_{2} \mathrm{Se}_{3}-\mathrm{GeSe}_{2}$ glasses previously reported in the literature. Moreover, the Raman spectra of glasses with $\mathrm{R}<1$ also display a broadening of the $175 \mathrm{~cm}^{-1}$ mode and the disappearance of the $215 \mathrm{~cm}^{-1}$ mode with increasing $\mathrm{Li}_{2} \mathrm{~S}$ content, along with a concomitant appearance of two new bands at 190 and $230 \mathrm{~cm}^{-1}$ (Fig. 2a). These additional modes must correspond to tetrahedral environments containing sulfur as these features are absent in the Raman spectra of binary $\mathrm{Ga}_{2} \mathrm{Se}_{3}-\mathrm{GeSe}_{2}$ glasses and their intensities increase with increasing S:Se ratio as the $\mathrm{GeSe}_{2}$ content decreases (Fig. 2a). This hypothesis is corroborated by the results of a previous study by Griffiths et al. on the effects of substitution of S for Se on the Raman spectrum of glassy $\mathrm{GeSe}_{2}$ [25]. Substitution of $\mathrm{S}$ for Se does not affect the tetrahedral character of the structural network and thus, similar spectral features are present and are progressively shifted to higher energy as the heavier Se atoms connecting the $\mathrm{GeX}_{4}$ tetrahedra are replaced with lighter $\mathrm{S}$ atoms. This substitution has a minor influence on the Raman shift of the $\left(X_{3}\right) \mathrm{Ge}-\mathrm{Ge}\left(\mathrm{X}_{3}\right)$ 
stretching mode as the main vibrational displacement is between the Ge atoms [26]. A mode at $190 \mathrm{~cm}^{-1}$ is expected for a homopolar $\left(\mathrm{Se}_{2} \mathrm{~S}\right) \mathrm{Ge}-\mathrm{Ge}\left(\mathrm{Se}_{2} \mathrm{~S}\right)$ dimer stretch. The rise in the mode at $226 \mathrm{~cm}^{-1}$ is also expected for the symmetric breathing mode of Ge/Ga tetrahedra containing one $\mathrm{S}$ and $3 \mathrm{Se}$ atoms. This spectral region for the $\mathrm{Li}_{2} \mathrm{~S}$ rich compositions with $\mathrm{R}>1$, only displays two prominent modes at $\sim 200$ and $225 \mathrm{~cm}^{-1}$ with the former mode being the dominant one, indicating that the tetrahedral network in the glasses is primarily composed of $\mathrm{Ge} / \mathrm{GaSe}_{4 / 2}$ tetrahedra (Fig. 2b). Increasing addition of $\mathrm{Li}_{2} \mathrm{~S}$ or $\mathrm{Ga}_{2} \mathrm{Se}_{3}$ to the binary $\mathrm{Li}_{2} \mathrm{~S}-\mathrm{GeSe}_{2}$ glass does not result in the appearance of any new modes, rather a broadening of the two modes at $\sim 200$ and $225 \mathrm{~cm}^{-1}$ along with a rise in the relative intensity of the $225 \mathrm{~cm}^{-1}$ mode are observed, which is consistent with the increasing replacement of Se with $\mathrm{S}$ in the tetrahedral units.

The broadened line shape between $225 \mathrm{~cm}^{-1}$ and $270 \mathrm{~cm}^{-1}$ is expected to contain the various $v_{1}$ modes of $\mathrm{GeSe}_{n} \mathrm{~S}_{4-\mathrm{n}}$ tetrahedra where $n=3,2$, or 1 as well as the mode corresponding to the out-of-phase stretching of the edge-sharing $\mathrm{GeSe}_{n} \mathrm{~S}_{4-\mathrm{n}}$ tetrahedra [15].

The spectral region between 270 and $450 \mathrm{~cm}^{-1}$ mostly consists of bands corresponding to the $v_{3}$ modes of $\mathrm{GeS}_{\mathrm{n}} \mathrm{Se}_{4-\mathrm{n}}$ tetrahedra with the highest intensity at $\sim 310 \mathrm{~cm}^{-1}$ indicating that the $\mathrm{GeSe}_{4}$ tetrahedra dominate the network. The frequencies of these modes continuously increase to up to $430 \mathrm{~cm}^{-1}$ to form a broad envelope in this spectral region in the Raman spectra of $\mathrm{R}>1$ glasses with high $\mathrm{S}$ :Se ratio (Fig. 2b). Additional intensity in this spectral region for the $\mathrm{R}>1$ compositions may arise from asymmetric stretching modes of Ge tetrahedra associated with nonbridging anions. The characteristic frequencie of these modes for NBSe is at $\sim 325 \mathrm{~cm}^{-1}[14]$ and that for NBS is at $\sim 420 \mathrm{~cm}^{-1}[27,28]$. Finally, the lack of intensity at $\sim 490 \mathrm{~cm}^{-1}$ in these Raman spectra indicates the absence of homopolar S-S bonds in these glasses [29]. 
The effect of introducing $\mathrm{S}$ to an alkali-modified $\mathrm{GeSe}_{2}$ glass can best be seen by comparing the Raman spectrum of the $40 \% \mathrm{Li}_{2} \mathrm{~S}-60 \% \mathrm{GeSe}_{2}$ glass to that of an analogous $\mathrm{Na}_{2} \mathrm{Se}-\mathrm{GeSe}_{2}$ composition reported in a previous study [14]. It is clear from a close inspection of these two spectra in Fig. $2 b$ that, in spite of their general similarity the addition of $S$ is manifested in significant broadening of the main breathing mode of $(\mathrm{Ga} / \mathrm{Ge}) \mathrm{Se}_{4 / 2}$ tetrahedra at $\sim 200 \mathrm{~cm}^{-1}$ and in a shift of the peak maximum to higher frequency. This change is likely due to the introduction of the additional breathing modes of mixed-chalcogen $\mathrm{GeS}_{\mathrm{n}} \mathrm{Se}_{4-\mathrm{n}}$ tetrahedra at correspondingly higher wavenumbers. Concomitant broadening of the bands between 270 and $350 \mathrm{~cm}^{-1}$ as well as the appearance of new bands in the region between $\sim 400-450 \mathrm{~cm}^{-1}$ are also observed in the spectrum of the $40 \% \mathrm{Li}_{2} \mathrm{~S}-60 \% \mathrm{GeSe}_{2}$ glass (Fig. 2b). These changes can be related to the introduction of the asymmetric stretching modes of the mixed-chalcogen $\mathrm{GeS}_{\mathrm{n}} \mathrm{Se}_{4-\mathrm{n}}$ tetrahedra with and without NBS.

All the LGGS/Se glasses appear to have some degree of hygroscopicity as monitored using Raman spectroscopy. The $\mathrm{R}>1$ compositions reacted upon immediate exposure to ambient atmosphere showing a rapid change of the original spectra. The $\mathrm{R}<1$ compositions did not show any change in their Raman spectral characteristics within the first 24 hours of exposure.

\subsection{NMR Spectroscopy}

\subsection{1. ${ }^{6} \mathrm{Li} \mathrm{NMR}$}

Despite the high natural abundance $(92.58 \%)$ of the ${ }^{7} \mathrm{Li}$ nuclide, the line width of the ${ }^{7} \mathrm{Li}$ NMR signal is observed to be on the order of $\sim 500 \mathrm{~Hz}$, resulting in insufficient resolution for identification of resonances with subtle chemical shift differences. In comparison, the ${ }^{6} \mathrm{Li} \mathrm{NMR}$ 
line shapes, on the other hand, are significantly narrower $(45-60 \mathrm{~Hz})$ due to weaker homonuclear dipolar interactions and quadrupolar broadening effects. Figure 3 shows the ${ }^{6}$ Li MAS NMR spectra of select glass compositions. All ${ }^{6} \mathrm{Li}$ MAS NMR spectra have a Lorentzian character to their line shapes and are characterized by two partially overlapping resonances for compositions with R>1 (Fig. 3). Simulations of these line shapes yield the chemical shift ranges for the two resonances to be $1.75-1.90 \mathrm{ppm}$ and 1.42-1.60 ppm (Table 2). Structural assignment of these two resonances is somewhat difficult due to the lack of a ${ }^{6} \mathrm{Li}$ chemical shift scale for chalcogenide compounds. However, systematic trends in chemical shifts from ${ }^{7}$ Li NMR should apply well to the ${ }^{6} \mathrm{Li}$ NMR spectra. The ${ }^{7} \mathrm{Li}$ isotropic chemical shift of crystalline $\mathrm{Li}_{2} \mathrm{~S}$ is found to be higher by $\sim 0.37 \mathrm{ppm}$ compared to that for crystalline $\mathrm{Li}_{2} \mathrm{Se}$ [30-32]. This difference agrees well with the separation between the two resonances observed in the ${ }^{6} \mathrm{Li}$ MAS NMR spectra of the glasses with $\mathrm{R}>1$ in Fig. 3, thus, allowing for the tentative assignment of the resonance at higher ppm values ( $\mathrm{Li}-\mathrm{II})$ to $\mathrm{Li}$ in a $\mathrm{S}$ rich environment and of that at lower ppm values ( $\mathrm{Li}-\mathrm{I})$ to $\mathrm{Li}$ in a Se rich environment. The Lorentzian character of the line shape and narrowed line width possibly suggests some degree of motional averaging from the mobility of Li ions in these glasses. The ${ }^{6} \mathrm{Li}$ MAS NMR spectrum of the glass with $\mathrm{R}<1$ is characterized by a single resonance centered at $0.93 \mathrm{ppm}$ whose chemical shift is consistent with $\mathrm{Li}$ coordinated to primarily to Se atoms [33].

\subsection{2. ${ }^{77}$ Se NMR}

The isotropic projection of the ${ }^{77} \mathrm{Se}$ MATPASS NMR spectrum is effectively an "infinite spinning speed" MAS spectrum with enhanced resolution while projection along the anisotropic dimension results in a spinning sideband pattern that allows for the extraction of the principle axes of the CSA tensor for a specific isotropic shift. The ${ }^{77}$ Se MATPASS NMR spectrum of the 
glass of composition $40 \mathrm{Li}_{2} \mathrm{~S}-10 \mathrm{Ga}_{2} \mathrm{Se}_{3}-50 \mathrm{GeSe}_{2}$ glass is shown in Fig. $4 \mathrm{a}$. The ${ }^{77} \mathrm{Se}$ isotropic projection spectrum can be simulated with two peaks centered at 316 and $100 \mathrm{ppm}$ (Fig. 4b) that can be assigned, respectively, to bridging selenium (BSe) sites in $\mathrm{Ga} / \mathrm{Ge}-\mathrm{Se}-\mathrm{Ge} / \mathrm{Ga}$ linkages between corner sharing $\mathrm{Ge}(\mathrm{Ga}) \mathrm{S}_{\mathrm{n}} \mathrm{Se}_{\mathrm{n}-4}$ tetrahedra and to NBSe sites in Ge-Se-Li environments $[16,34,35]$. The magnitude of the CSA $\Delta$ for these two sites can be gleaned from the 2D contour plot where it is clear that $\Delta$ for the NBSe site is larger than that of the BSe site, consistent with previous reports of such sites in selenide glasses with compensated networks [16, 35]. Simulation of the spinning sideband patterns for these two peaks in the anisotropic dimension (Fig. $4 \mathrm{c})$ yields a CSA tensor with $\Delta=210 \mathrm{ppm}(\Delta=-405 \mathrm{ppm})$ and $\eta=0.9(\eta=0.6)$ for the isotropic peak at $316 \mathrm{ppm}(100 \mathrm{ppm})$. These CSA values are consistent with previous reports $[16,35]$. These isotropic shifts and CSA parameters are used to constrain the simulation of the ${ }^{77}$ Se MAS NMR spectra of compositionally closely related glasses with $\mathrm{R}>1$ (Fig. 5). These MAS spectra are significantly broadened by the CSA and the chemical shift distribution. However, using the $\delta_{\text {iso }}$ and CSA parameters obtained from the ${ }^{77}$ Se MATPASS/CPMG spectrum the MAS spectrum of the same glass can be accurately simulated to obtain site fractions that are consistent between the two experiments. The remaining ${ }^{77} \mathrm{Se}$ MAS NMR spectra of the R>1 glasses can be simulated well with the same $\delta_{\text {iso }}$ and CSA parameters for the BSe and NBSe environments. These simulation parameters are listed in Table 2.

The results of these simulations show a steady increase in the fraction NBSe environments relative to the $\mathrm{BSe}$ fraction with increasing $\mathrm{Li}_{2} \mathrm{~S}$ content. In addition there is an increase in the NBSe environment when $\mathrm{Ga}_{2} \mathrm{Se}_{3}$ is added to replace $\mathrm{GeSe}_{2}$ in the pseudo-binary $\mathrm{Li}_{2} \mathrm{~S}-\mathrm{GeSe}_{2}$ glass system. It is interesting to note that the isotropic chemical shift of the BSe environment (316 ppm) in these $\mathrm{R}>1$ glasses is significantly lower than the value typically 
observed in Ge-Se glasses (380-400 ppm). This difference is likely related to the substitution of $\mathrm{S}$ in the nearest-neighbor environment of Ge atoms, as Ge-S bonds are shorter $(\sim 2.22 \AA)$ and more ionic compared to the Ge-Se bonds $(\sim 2.35 \AA)$ and the electronic and steric effects associated with their coexistence in the $\mathrm{GeX}_{4}$ tetrahedra may easily influence the ${ }^{77} \mathrm{Se}$ chemical shift [36].

The ${ }^{77}$ Se MAS NMR spectra for the $\mathrm{R}<1$ glasses can also be simulated with two resonances centered near $\sim 400 \mathrm{ppm}$ and $\sim 180 \mathrm{ppm}$ (Fig. 5, Table 2). These peak positions are consistent with those reported in the literature for binary $\mathrm{Ga}_{2} \mathrm{Se}_{3}-\mathrm{GeSe}_{2}$ glasses with $\mathrm{R}=0$. The resonance at $\sim 400 \mathrm{ppm}$ was previously ascribed to Ge/Ga-Se-Ge type BSe environments and that at $\sim 180 \mathrm{ppm}$ was assigned to $(\mathrm{Ga} / \mathrm{Ge})-\mathrm{Se}-\mathrm{Ge}-\mathrm{Ge}$ sites where the $\mathrm{Se}$ atom is in an ethane like unit where one of the nearest neighbor Ge atoms is homopolar bonded to another Ge atom [37, 38]. A gradual increase in the relative fraction of the $(\mathrm{Ga} / \mathrm{Ge})-\mathrm{Se}-\mathrm{Ge}-\mathrm{Ge}$ sites relative to the BSe sites is observed in these $\mathrm{R}<1$ glasses, with decreasing $\mathrm{GeSe}_{2}$ content (Fig. 5, Table 2). The inset of Fig. 5 highlights the effect of S substitution on the ${ }^{77}$ Se isotropic chemical shift of the BSe sites in the LGGS/Se glasses. A similar effect was reported in the literature for various S substituted Se compounds [39-41].

\subsection{3. ${ }^{71} \mathrm{Ga}$ QMAT NMR}

The ${ }^{71}$ Ga QMAT central transition spectra for the representative glasses with $\mathrm{R}>1$ and $\mathrm{R}<1$ are shown in Fig. 6. These ${ }^{71} \mathrm{Ga}$ QMAT spectra display a single peak with a low frequency tail characteristic of a distribution of electric field gradients at the Ga site, typical of disordered materials. Simulation of these central transition line shapes using the Czjzek model for the distribution of $\mathrm{C}_{\mathrm{q}}$ yields an isotropic shift of $\sim 160 \mathrm{ppm}$ and a $\mathrm{C}_{\mathrm{q}}$ of $\sim 10 \mathrm{MHz}$ for both 
compositions with $\mathrm{R}<1$. These $\mathrm{NMR}$ parameters are in good agreement with previously published reports of the ${ }^{71} \mathrm{Ga} \mathrm{NMR}$ spectra in binary $\mathrm{Ga}_{2} \mathrm{Se}_{3}-\mathrm{GeSe}_{2}$ glasses corresponding to tetrahedral $\mathrm{GaSe}_{4 / 2}$ environments $[15,16,38]$. On the other hand, the ${ }^{71} \mathrm{Ga}$ QMAT spectrum for the $\mathrm{R}>1$ glass is characterized by a $\delta_{\text {iso }}$ of $\sim 320 \mathrm{ppm}$ and a $\mathrm{C}_{\mathrm{q}}$ of $11 \mathrm{MHz}$. This spectrum is rather similar to that reported for the $\mathrm{GaS}_{4 / 2}$ environment in Ge-Ga-P-S glasses, which suggests that Ga is fourfold coordinated and is predominantly bonded to the $\mathrm{S}$ atoms in this glass with $\mathrm{R}=4$ [42].

\section{Discussion}

When taken together the Raman and multinuclear NMR spectroscopic results indicate that the structure of the LGGS/Se glasses consists of a network of primarily corner sharing $\mathrm{GeSe}_{4 / 2}$ and $\mathrm{GaSe}_{4 / 2}$ tetrahedra. As sulfur is introduced into the glass as a second chalcogen, the appearance of additional vibrational modes in the Raman spectra suggests the formation of mixed chalcogen $\mathrm{GeS}_{\mathrm{n}} \mathrm{Se}_{4-\mathrm{n}}$ tetrahedra. Otherwise, the general structural evolution in the LGGS/Se glasses with composition is in agreement with the results of previous studies on isoelectronic selenide analogues in the stoichiometric $\mathrm{Ag}_{2} \mathrm{Se} / \mathrm{Na}_{2} \mathrm{Se} / \mathrm{BaSe}-\mathrm{Ga}_{2} \mathrm{Se}_{3}-\mathrm{GeSe}_{2}$ systems $[14-16,22]$ where the coordination numbers of $\mathrm{Ge}, \mathrm{Ga}$, and $\mathrm{Se}$ are 4, 4, and 2, respectively, irrespective of glass composition. For $\mathrm{R}>1$, these selenide glasses contain NBSe that are charge compensated by the modifier cations. On the other hand, the $\mathrm{R}<1$ glasses are too deficient in chalcogen content to satisfy the tetrahedral coordination of Ga atoms and this deficiency is accommodated by the formation of homopolar Ge-Ge bonds. Furthermore, the $\left[\mathrm{GaSe}_{4 / 2}\right]^{-}$tetrahedra in glasses with either $\mathrm{R}<1$ or $\mathrm{R}>1$ are charge balanced by the modifier cation similar to the scenario in alkali/alkaline-earth aluminosilicate glasses. 
In spite of these general similarities, the compositional evolution of the network structure of mixed-chalcogen LGGS/Se glasses has additional complexities associated with the chemical ordering of the $\mathrm{S} v s$. Se atoms, which is found to be quite different between glasses with $\mathrm{R}>1$ and those with $\mathrm{R}<1$. The Raman spectra of the $\mathrm{R}>1$ glasses (Fig. 2b) display additional bands at wavenumbers higher than $200 \mathrm{~cm}^{-1}$, corresponding to $\mathrm{GeS}_{\mathrm{n}} \mathrm{Se}_{4-\mathrm{n}}$ units with $\mathrm{n}>1$ and from contributions of NBSe at $\sim 325 \mathrm{~cm}^{-1}$ and of NBS at $420 \mathrm{~cm}^{-1}$. These results indicate that a majority of the $\mathrm{Ge} / \mathrm{Ga}$ tetrahedra have at least one $\mathrm{S}$ and both Se and $\mathrm{S}$ can form non-bridging environments. The mixed chalcogen tetrahedral network is thus, modified by the addition of $\mathrm{Li}$ to form NBSe and NBS species, of which the concentration of the former can be directly identified and its concentration can be estimated using ${ }^{77}$ Se NMR (Fig. 5). As shown in Fig. 5 and Table 2, the simulation of the ${ }^{77} \mathrm{Se}$ MAS NMR spectrum of the pseudo-binary $40 \% \mathrm{Li}_{2} \mathrm{~S}$ $60 \% \mathrm{GeSe}_{2}$ glass indicates that $\sim 40 \%$ of the Se atoms are NBSe, which, within experimental error, compares well with the expected value of $50 \%$ for equal probability of formation of NBS and NBSe. However, the pseudo-ternary composition $40 \% \mathrm{Li}_{2} \mathrm{~S}-10 \% \mathrm{Ga}_{2} \mathrm{Se}_{3}-50 \% \mathrm{GeSe}_{2}$ with the same $\mathrm{Li}_{2} \mathrm{~S}$ content shows the opposite: simulation of the ${ }^{77} \mathrm{Se}$ MAS NMR spectrum yields $67 \%$ NBSe while the predicted amount from a random probability model is only $42 \%$ NBSe. In fact, the experimentally observed fraction of NBSe in both glasses with $\mathrm{R}>1$ is significantly larger than that expected from the random model (Table 2), which suggests a strong bonding preference between $\mathrm{Ga}$ and $\mathrm{S}$ in $\mathrm{R}>1$ glasses. This interpretation is corroborated by the ${ }^{71} \mathrm{Ga}$ NMR results as the ${ }^{71} \mathrm{Ga} \delta_{\text {iso }}$ shows an abrupt shift from $\sim 160 \mathrm{ppm}$ in $\mathrm{R}<1$ glasses to $\sim 320 \mathrm{ppm}$ in $\mathrm{R}>1$ glasses, with the latter shift being characteristic of $\mathrm{Ga}$ atoms in tetrahedral coordination with $\mathrm{S}$ atoms. The preference to form Ga-S over Ge-S bonds in $\mathrm{R}>1$ glasses is likely due to the greater electronegativity difference between $\mathrm{Ga}$ and $\mathrm{S}$ than that between $\mathrm{Ge}$ and $\mathrm{S}$, thus creating a 
stronger heteropolar bond. It is important to note here that the ${ }^{6} \mathrm{Li} \mathrm{NMR}$ spectra of the pseudoternary LGGS/Se glasses with R>1 show the existence of two different Li environments, one of which is characterized by a preference for bonding with $\mathrm{S}$ atoms. This result is consistent with the scenario that a large fraction of $\mathrm{Li}^{+}$charge balances the $\left[\mathrm{GaS}_{4 / 2}\right]^{-}$tetrahedra in the structure of these glasses. The second $\mathrm{Li}$ environment has a higher $\mathrm{Se}: \mathrm{S}$ ratio in the nearest neighbor coordination shell, which would suggest that, besides $\mathrm{S}$, these $\mathrm{Li}$ are bonded to NBSe atoms that are in the nearest neighbor shell of Ge atoms- thus forming Ge-NBSe-Li linkages. However, and more interestingly, two ${ }^{6} \mathrm{Li}$ resonances with similar $\delta_{\text {iso }}$ are also observed in the ${ }^{6} \mathrm{Li}$ MAS spectrum of the pseudo-binary $40 \% \mathrm{Li}_{2} \mathrm{~S}-60 \% \mathrm{GeSe}_{2}$ glass. The stochiometry of this glass implies the formation of $1.33 \mathrm{NBS} / \mathrm{Se}$ per Ge tetrahedron in the structure, i.e. the network must consist primarily of a mixture of Ge tetrahedra with 1 and 2 NBS/Se in an approximate ratio of 67:33. Therefore, considering a $\mathrm{S}: \mathrm{Se}$ ratio of 1:3, the presence of two different Li environments in this glass in sub-equal concentration may suggest a spatial segregation of these two types of tetrahedra, instead of a segregation of $\mathrm{S}$ and $\mathrm{Se}$, in the structural network. This structural scenario would imply the presence of $\mathrm{GeX}_{4}$ tetrahedra in configurations with either one NBSe or with 1 NBS +1 NBSe.

In contrast, the $\mathrm{R}<1$ glasses are deficient in chalcogen and form homopolar Ge-Ge bonds to accommodate this deficiency as the Raman spectra (Fig. 2a) of these glasses show a rise in intensity for the $190 \mathrm{~cm}^{-1}$ mode corresponding to homopolar $\left(\mathrm{Se}_{2} \mathrm{~S}\right) \mathrm{Ge}-\mathrm{Ge}\left(\mathrm{Se}_{2} \mathrm{~S}\right)$ dimer stretching. The ${ }^{6} \mathrm{Li}$ and ${ }^{71} \mathrm{Ga}$ NMR spectra (Figs. 3,6) are consistent with this scenario, showing only resonances corresponding to $\mathrm{Li}$ and $\mathrm{Ga}$ coordinated exclusively to $\mathrm{Se}$ atoms with $\mathrm{Ga}$ being in tetrahedral coordination. These results suggest that the primary role of $\mathrm{Li}^{+}$is to charge 
balance the $\left[\mathrm{GaSe}_{4 / 2}\right]^{-}$tetrahedra in the structure of $\mathrm{R}<1$ glasses, as neither the Raman nor ${ }^{77} \mathrm{Se}$ NMR spectra show any evidence for the presence of NBS/Se.

This structural scenario for the LGGS/Se glasses is consistent with the observed compositional variation of $\mathrm{T}_{\mathrm{g}}$ (Table 1). Overall the same compositional trends were also observed in analogous selenide glasses in the stoichiometric $\mathrm{Ag}_{2} \mathrm{Se} / \mathrm{Na} 2 \mathrm{Se} / \mathrm{BaSe}-\mathrm{Ga}_{2} \mathrm{Se}_{3}-\mathrm{GeSe}_{2}$ systems $[14,16,22]$. The $\mathrm{T}_{\mathrm{g}}$ of the LGGS/Se glasses with $\mathrm{R}>1$ is significantly lower than that of glasses with $\mathrm{R}<1$. This difference can be readily ascribed to the loss of network connectivity and lowering of average coordination number via formation of NBS and NBSe in modifier rich glasses with $\mathrm{R}>1$. For $\mathrm{R}<1$ glasses, $\mathrm{T}_{\mathrm{g}}$ increases only slightly as $\mathrm{Ga}_{2} \mathrm{Se}_{3}$ replaces $\mathrm{GeSe}_{2}$, which is consistent with an increase in the average bond energy of the network as Ga-Se bonds are stronger than Ge-Se bonds [43, 44]. Overall, the narrow range of $\mathrm{T}_{\mathrm{g}}$ values for these glasses $\left(\sim 360-380^{\circ} \mathrm{C}\right)$ attests to the fact that the structural network is dominated by the corner-shared $(\mathrm{Ga}, \mathrm{Ge}) \mathrm{X}_{4 / 2}$ tetrahedra, such that the influence of the modifier is minimal. Within the $\mathrm{R}>1$ glasses $\mathrm{T}_{\mathrm{g}}$ decreases with increasing $\mathrm{Li}_{2} \mathrm{~S}$ content as it leads to increasing concentration of NBS and NBSe atoms that act to depolymerize the network. The influence of $\mathrm{S}$ on the network is best illustrated by comparing $\mathrm{T}_{\mathrm{g}}$ values of the pseudo-binary $\mathrm{Li}_{2} \mathrm{~S}-\mathrm{GeS}_{2}, \mathrm{Li}_{2} \mathrm{~S}-\mathrm{GeSe}_{2}$, and $\mathrm{Li}_{2} \mathrm{Se}-$ $\mathrm{GeSe}_{2}$ systems. For an equal modifier content of $40 \mathrm{~mol} \%$, the pure sulfide system has a $\mathrm{T}_{\mathrm{g}}$ of $324^{\circ} \mathrm{C}$, and the pure selenide system has a $\mathrm{T}_{\mathrm{g}}$ of $248^{\circ} \mathrm{C}$ [9] while the mixed-chalcogen $\mathrm{Li}_{2} \mathrm{~S}$ $\mathrm{GeSe}_{2}$ glass studied here has a $\mathrm{T}_{\mathrm{g}}$ of $293^{\circ} \mathrm{C}$. It is clear from this comparison that for similar degrees of network connectivity, $\mathrm{T}_{\mathrm{g}}$ is a function of the average bond strength of the network which is the highest in the pure sulfide system. The $\mathrm{T}_{\mathrm{g}}$ increases upon addition of $\mathrm{Ga}_{2} \mathrm{Se}_{3}$ to the $\mathrm{Li}_{2} \mathrm{~S}-\mathrm{GeSe}_{2}$ glass as the network is re-polymerized via removal of non-bridging chalcogen and 
possibly due to a shift in the type of non-bridging chalcogen from a mix of NBS and NBSe to almost exclusively NBSe.

\section{Conclusions}

The structure of the LGGS/Se glasses is characterized by a network of predominantly corner-sharing $(\mathrm{Ga} / \mathrm{Ge})(\mathrm{Se}, \mathrm{S})_{4 / 2}$ tetrahedra. The negatively charged $\mathrm{Ga}(\mathrm{Se}, \mathrm{S})_{4 / 2}$ tetrahedra are charge balanced by the Li cations. Glasses with R>1 contain NBS and NBSe species that result in a lowering of the network connectivity consistent with a lowering in $\mathrm{T}_{\mathrm{g}}$. On the other hand, glasses with $\mathrm{R}<1$ are deficient in chalcogen required to satisfy the tetrahedral coordination of both Ge and Ga atoms. This deficiency is accommodated via formation of Ge-Ge homopolar bonds. $\mathrm{S}$ atoms show a strong preference for bonding to these $\mathrm{Ge}$ atoms in glasses with $\mathrm{R}<1$. In contrast, for glasses with $\mathrm{R}>1, \mathrm{~S}$ preferentially bonds to $\mathrm{Ga}$, which substantially increases the NBSe:NBS ratio compared to its expected value for a random distribution of chalcogen atoms in the structure. This preferential chemical ordering of $S$ is likely related to the higher ionicity of the Ge/Ga-S bonds compared to their Se analogues.

\section{Acknowledgments}

This work was supported by the grants DMR1104869 and DMR1505185 from the National Science Foundation. The authors thank Stephen Currie at Corning Inc. for help with the glass synthesis and Drs. Zhehong Gan and Ivan Hung at the National High Magnetic Field Laboratory (Tallahassee, Florida) for their help with the collection of the $2 \mathrm{D}{ }^{77}$ Se MATPASS/CPMG NMR data at high magnetic field. 


\section{References}

1. Eggleton, B.J., B. Luther-Davies, and K. Richardson, Chalcogenide photonics. Nat Photon, 2011. 5(3): p. 141-148.

2. Sousa, V., Chalcogenide materials and their application to Non-Volatile Memories. Microelectronic Engineering, 2011. 88(5): p. 807-813.

3. Tatsumisago, M., Glassy materials based on Li2S for all-solid-state lithium secondary batteries. Solid State Ionics, 2004. 175(1-4): p. 13-18.

4. Yang, G., et al., Correlation between structure and physical properties of chalcogenide glasses in theAsxSe1-xsystem. Physical Review B, 2010. 82(19).

5. Yang, G., et al., Physical properties of the GexSe1-x glasses in the $0<x<0.42$ range in correlation with their structure. Journal of Non-Crystalline Solids, 2013. 377: p. 54-59.

6. Gjersing, E.L., S. Sen, and B.G. Aitken, Structure, Connectivity, and Configurational Entropy of GexSe100-x Glasses: Results from 77Se MAS NMR Spectroscopy. Journal of Physical Chemistry C, 2010. 114(18): p. 8601-8608.

7. Sen, S., et al., Structure, topology and chemical order in Ge-As-Te glasses: a high-energy x-ray diffraction study. J Phys Condens Matter, 2010. 22(40): p. 405401.

8. Bytchkov, A., et al., Unraveling the atomic structure of Ge-rich sulfide glasses. Phys Chem Chem Phys, 2013. 15(22): p. 8487-94.

9. Michel-Lledos, V., A. Pradel, and M. Ribes, Lithium conductive selenide glasses. European Journal of Solid State Inorganic Chemistry, 1992. 29(2): p. 301-310.

10. Pradel, A. and M. Ribes, Lithium chalcogenide conductive glasses. Materials Chemistry and Physics 1989. 23: p. 121-142.

11. Ribes, M., B. Barrau, and J.L. Souquet, Sulfide glasses: glass forming region, structure and ionic conduction of glasses in $\mathrm{Na}_{2} \mathrm{~S}-\mathrm{XS}_{2}(\mathrm{X}=\mathrm{Si} ; \mathrm{Ge}), \mathrm{Na}_{2} \mathrm{~S}_{-} \mathrm{P}_{2} \mathrm{~S}_{5}$ and $\mathrm{Li}_{2} \mathrm{~S}-\mathrm{GeS} \mathrm{S}_{2}$ systems. Journal of Non-Crystalline Solids, 1980. 38 \& 39: p. 271-276.

12. Calvez, L., et al., Influence of gallium and alkali halide addition on the optical and thermo-mechanical properties of GeSe2-Ga2Se3 glass. Applied Physics A, 2007. 89(1): p. $183-188$.

13. Harbison, B.B., C.I. Merzbacher, and I.D. Aggarwal, Preparation and properties of BaSGa2S3-GeS2 glasses. Journal of Non-Crystalline Solids, 1997. 213 \& 214: p. 16-21. 
14. Mao, A.W., et al., Synthesis and characterization of ternary glasses in the system Na2SeGa2Se3-GeSe2. Journal of Non-Crystalline Solids, 2014. 404: p. 91-97.

15. Mao, A.W., et al., Structure and bonding characteristics of chalcogenide glasses in the system BaSeGa2Se3GeSe2. Journal of Non-Crystalline Solids, 2013. 375: p. 40-46.

16. Marple, M.A.T., et al., Structure and physical properties of glasses in the system Ag2SeGa2Se3-GeSe2. Journal of Non-Crystalline Solids, 2016. 437: p. 34-42.

17. Hung, I. and Z. Gan, A magic-angle turning NMR experiment for separating spinning sidebands of half-integer quadrupolar nuclei. Chemical Physics Letters, 2010. 496(1-3): p. 162-166.

18. Hung, I., et al., MATPASS/CPMG: a sensitivity enhanced magic-angle spinning sideband separation experiment for disordered solids. J Magn Reson, 2012. 221: p. 103-9.

19. States, D.J., R.A. Haberkorn, and D.J. Ruben, A Two-Dimensional Nuclear Overhauser Experiment with Pure Absorption Phase in Four Quadrants. Journal of Magnetic Resonance, 1982. 48: p. 286-292.

20. Mehring, M., Principles of High Resolution NMR in Solids. 1983, Berlin: SpringerVerlag.

21. Massiot, D., et al., Modelling one-and two-dimensional solid-state NMR spectra. Magnetic Resonance in Chemistry, 2002. 40(1): p. 70-76.

22. Mao, A.W., B.G. Aitken, and S. Sen, Synthesis and physical properties of chalcogenide glasses in the system BaSe-Ga2Se3-GeSe2. Journal of Non-Crystalline Solids, 2013. 369: p. 38-43.

23. Saienga, J., et al., Preparation and characterization of glasses in the LiI+LiS+GeS+GaS system. Solid State Ionics, 2005. 176(13-14): p. 1229-1236.

24. Yamashita, M., Formation and ionic conductivity of Li2S-GeS2-Ga2S3 glasses and thin films. Solid State Ionics, 2003. 158(1-2): p. 151-156.

25. Griffiths, J.E., et al., Raman spectra and athermal laser annealing ofGe(SxSe1-x)2glasses. Physical Review B, 1983. 28(8): p. 4444-4453.

26. Lucovsky, G., et al., Structural interpretation of the infrared and Raman spectra of glasses in the alloy systemGe1-xSx. Physical Review B, 1974. 10(12): p. 5134-5146.

27. Souquet, J.L., et al., Glass formation and ionic conduction in the $\mathrm{M}_{2} \mathrm{~S}-\mathrm{GeS} \mathrm{S}_{2}(\mathrm{M}=\mathrm{Li}, \mathrm{Na}$, Ag) systems. Solid State Ionics, 1981. 3/4: p. 317-321. 
28. Yao, W., K. Berg, and S. Martin, Structure and properties of glasses in the $M I+M 2 S+(0.1 G a 2 S 3+0.9 G e S 2), M=L i, N a, K$ and Cs, system. Journal of NonCrystalline Solids, 2008. 354(18): p. 2045-2053.

29. Blaineau, S. and P. Jund, Vibrational signature of broken chemical order in aGeS2glass: A molecular dynamics simulation. Physical Review B, 2004. 69(6).

30. Francisco, R.H.P., T. Tepe, and H. Eckert, A study of the system Li-P-Se. Journal of Solid State Chemistry, 1993. 107: p. 452-459.

31. Kim, J. and T. Hughbanks, Synthesis and structures of new ternary aluminum chalcogenides: LiAlSe $_{2}, \alpha$-LiAlTe ${ }_{2}$, and $\beta$-LiAlTe 2 . Inorganic Chemistry, 2000. 39(14): p. 3092-3097.

32. Patel, M.U., et al., X-ray absorption near-edge structure and nuclear magnetic resonance study of the lithium-sulfur battery and its components. Chemphyschem, 2014. 15(5): p. 894-904.

33. Pütz, S., et al., Li7B7Se15: A novel selenoborate with a zeolite-like polymeric anion structure. Solid State Sciences, 2006. 8(7): p. 764-772.

34. Edwards, T.G., S. Sen, and E.L. Gjersing, A combined 77Se NMR and Raman spectroscopic study of the structure of GexSe1-x glasses: Towards a self consistent structural model. Journal of Non-Crystalline Solids, 2012. 358(3): p. 609-614.

35. Kaseman, D.C., et al., Observation of a continuous random network structure in $\mathrm{Ge}(x) \mathrm{Se}(100-x)$ glasses: results from high-resolution 77Se MATPASS/CPMG NMR spectroscopy. J Phys Chem B, 2013. 117(3): p. 949-54.

36. Eckert, H., et al., Solid state NMR chemical shifts of chalcogenides and pnictides, in Nuclear Magnetic Shieldings and Molecular Structure, J.A. Tossell, Editor. 1993, Springer Netherlands p. 49-73.

37. Mao, A.W., et al., Structure of glasses in the pseudobinary system $\mathrm{Ga}(2) \mathrm{Se}(3)-\mathrm{GeSe}(2)$ : violation of chemical order and 8-N coordination rule. J Phys Chem B, 2013. 117(51): p. 16594-601.

38. Mao, A.W., et al., Mechanisms of structural accommodation of Se deficiency in binary Ga2Se3-GeSe2 glasses: Results from 77Se MATPASS/CPMG NMR spectroscopy. Journal of Non-Crystalline Solids, 2015. 410: p. 14-19. 
39. Björgvinsson, M., J.F. Sawyer, and G.J. Schrobilgen, Crystal structures of potassium cryptated salts of the $\mathrm{TeSe}_{2}{ }^{2-}$, pyradmidal $\mathrm{TeSe}_{3}{ }^{2-}$, and mixed compounds containing pyramidal $\mathrm{TeSe}_{3}{ }^{2-}$ and chain $\mathrm{Te}_{x} \mathrm{Se}_{4-x}{ }^{2-}$ anions and ${ }^{77} \mathrm{Se}$ and ${ }^{125}$ Te solution NMR studies of the pyramidal selenothiotellurite anions $\mathrm{TeS}_{m} \mathrm{Se}_{3-m}{ }^{2-}(m=0-3)$. Inorganic Chemistry, 1991. 30(22): p. 4238-4245.

40. Ratcliffe, C.I., et al., Solid state NMR studies of photoluminescent cadmium chalcogenide nanoparticles. Phys Chem Chem Phys, 2006. 8(30): p. 3510-9.

41. Zhang, J., et al., Bright Gradient-Alloyed CdSexS1-xQuantum Dots Exhibiting Cyan-Blue Emission. Chemistry of Materials, 2016. 28(2): p. 618-625.

42. Youngman, R.E. and B.G. Aitken, Structure and properties of GeGaP sulfide glasses. Journal of Non-Crystalline Solids, 2004. 345-346: p. 50-55.

43. Afifi, M.A., et al., Electrical and thermal properties of chalcogenide glass system Se75Ge25-xSbx. Applied Physics A, 1992. 55: p. 167-169.

44. Nedeva, Y., et al., Compositional dependance of the optical properties of the Ge-Se-Ga glasses. Journal of Optoelectronics and Advanced Materials, 2001. 3(2): p. 433-436. 
Table 1: Nominal composition ( $\mathrm{mol} \%), \mathrm{T}_{\mathrm{g}}$, and $\mathrm{T}_{\mathrm{x}}$ (crystallization temperature) for all homogeneous LGGS/Se glasses synthesized in this study.

\begin{tabular}{llllll}
\hline $\mathrm{Li}_{2} \mathrm{~S}$ & $\mathrm{Ga}_{2} \mathrm{Se}_{3}$ & $\mathrm{GeSe}_{2}$ & $\mathrm{~S} /(\mathrm{S}+\mathrm{Se})$ & $\mathrm{T}_{\mathrm{g}}\left({ }^{\circ} \mathrm{C}\right)$ & $\mathrm{T}_{\mathrm{x}}\left({ }^{\circ} \mathrm{C}\right)$ \\
\hline 40 & 0 & 60 & 0.250 & 293 & 353 \\
40 & 10 & 50 & 0.235 & 304 & 370 \\
45 & 10 & 45 & 0.273 & 290 & 366 \\
50 & 10 & 40 & 0.313 & 287 & 366 \\
5 & 20 & 75 & & & 433 \\
7.5 & 32.5 & 60 & 0.023 & 363 & 423 \\
15 & 25 & 60 & 0.033 & 366 & 421 \\
20 & 30 & 50 & 0.071 & 369 & 419 \\
\hline
\end{tabular}


Table 2: Line shape simulation parameters for the ${ }^{77} \mathrm{Se}$ and ${ }^{6} \mathrm{Li}$ MAS NMR spectra of the LGGS/Se glasses (see Figs. 3 \& 5).

\begin{tabular}{|c|c|c|c|c|c|}
\hline \multicolumn{6}{|c|}{${ }^{7}$ Se NMR Parameters } \\
\hline $\mathrm{Li}_{2} \mathrm{~S}: \mathrm{Ga}_{2} \mathrm{Se}_{3}: \mathrm{GeSe}_{2}$ & $\begin{array}{l}\delta_{\text {iso }}( \pm 10 \\
\text { ppm })\end{array}$ & Width (ppm) & $\begin{array}{c}\Delta \\
(\mathrm{ppm})\end{array}$ & $\eta$ & $\begin{array}{c}\text { Relative fraction }( \pm \\
10 \%)\end{array}$ \\
\hline \multicolumn{6}{|l|}{$5: 20: 75$} \\
\hline Ge-Se-Ge & 400 & 320 & $250 *$ & $0.9 *$ & 56 \\
\hline Ge-Se-Ge-Ge & 170 & 320 & $250 *$ & $0.9 *$ & 44 \\
\hline \multicolumn{6}{|l|}{$15: 25: 60$} \\
\hline Ge-Se-Ge & 400 & 320 & $250 *$ & $0.9 *$ & 40 \\
\hline Ge-Se-Ge-Ge & 130 & 320 & $250 *$ & $0.9 *$ & 60 \\
\hline \multicolumn{6}{|l|}{$20: 30: 50$} \\
\hline Ge-Se-Ge & 400 & 320 & $250 *$ & $0.9^{*}$ & 32 \\
\hline Ge-Se-Ge-Ge & 110 & 320 & $250 *$ & $0.9 *$ & 68 \\
\hline \multicolumn{6}{|l|}{ 40:00:60 } \\
\hline Ge-Se-Ge & 330 & 250 & 210 & 0.9 & 62 \\
\hline Ge-Se-Li & 100 & 240 & -405 & 0.6 & 38 \\
\hline \multicolumn{6}{|l|}{$40: 10: 50$} \\
\hline Ge-Se-Ge & 320 & 250 & 210 & 0.9 & 33 \\
\hline Ge-Se-Li & 100 & 240 & -405 & 0.6 & 67 \\
\hline \multicolumn{6}{|l|}{ 50:10:40 } \\
\hline Ge-Se-Ge & $\begin{array}{l}320 \\
100\end{array}$ & $\begin{array}{l}250 \\
240\end{array}$ & -405 & 0.6 & $\begin{array}{l}11 \\
89\end{array}$ \\
\hline \multicolumn{6}{|l|}{ 40:10:50 MATPASS } \\
\hline Ge-Se-Ge & 316 & 180 & 210 & 0.9 & 33 \\
\hline Ge-Se-Li & 100 & 190 & -405 & 0.6 & 67 \\
\hline
\end{tabular}

\section{${ }^{6} \mathrm{Li}$ NMR Parameters}

\begin{tabular}{|c|c|c|c|c|}
\hline $\mathrm{Li}_{2} \mathrm{~S}: \mathrm{Ga}_{2} \mathrm{Se}_{3}: \mathrm{GeSe}_{2}$ & $\begin{array}{c}\delta_{\text {iso }}( \pm 10 \\
\text { ppm })\end{array}$ & Width (ppm) & $x G(1-x) L^{* *}$ & Relative fraction $( \pm 5 \%)$ \\
\hline \multicolumn{5}{|l|}{$20: 30: 50$} \\
\hline $\mathbf{L i}-\mathrm{Se}$ & 0.93 & 0.61 & 0.59 & 100 \\
\hline \multicolumn{5}{|l|}{$40: 10: 50$} \\
\hline Li-I & 1.42 & 0.36 & 0.27 & 37 \\
\hline Li-II & 1.75 & 0.36 & 0.27 & 63 \\
\hline \multicolumn{5}{|l|}{$50: 10: 40$} \\
\hline Li-I & 1.50 & 0.35 & 0.27 & 37 \\
\hline Li-II & 1.84 & 0.35 & 0.27 & 63 \\
\hline \multicolumn{5}{|l|}{ 40:00:60 } \\
\hline Li-I & 1.60 & 0.38 & 0.22 & 40 \\
\hline Li-II & 1.90 & 0.38 & 0.22 & 60 \\
\hline
\end{tabular}

*denotes $\Delta$ and $\eta$ values from Mao et al.[37]. Other $\Delta$ and $\eta$ values are from the simulation of the MATPASS anisotropic spectra (see text for details)

** denotes fractional Gaussian character of the mixed Gaussian-Lorentzian line shape 


\section{Figure Captions}

Figure 1. Glass formation region of the LGGS/Se system. Green circles denote homogeneous glass forming compositions. The blue circles are homogeneous glass compositions of the $\mathrm{Ga}_{2} \mathrm{Se}_{3}-\mathrm{GeSe}_{2}$ join from Mao et al. [36]. The green area surrounding the circles marks the continuous glass formation regions. Compositions shown with black squares devitrified upon quenching.

Figure 2 . Raman spectra of homogeneous LGGS/Se glasses with $R<1$ (a) and with $R>1$ (b). The inset in (a) is an expanded view of the spectra in the region marked by the dashed box. Asterisks mark the peak corresponding to the $\mathrm{Al}$ alloy sample holder. Glass composition is denoted alongside each spectrum in the form of three numbers separated by short dashes that from left to right correspond to the $\mathrm{mol} \% \mathrm{Li}_{2} \mathrm{~S}, \mathrm{Ga}_{2} \mathrm{Se}_{3}$ and $\mathrm{GeSe}_{2}$, respectively. Dashed spectra of $40 \% \mathrm{Na}_{2} \mathrm{Se}-60 \% \mathrm{GeSe}_{2}$ from Mao et al. [14].

Figure 3. ${ }^{6} \mathrm{Li}$ MAS NMR spectra of representative LGGS/Se glasses with $\mathrm{R}<1$ and $\mathrm{R}>1$. Glass composition is denoted alongside each spectrum using the same convention as in Fig. 2. Experimental and simulated spectra are shown with solid black lines and dashed red lines, respectively. Two components $\mathrm{Li}-\mathrm{I}$ (orange) and $\mathrm{Li}$-II (green) are used to simulate the line shapes for the R>1 glasses. All line shapes have a mixed Gaussian-Lorentzian character (see Table 2).

Figure 4. (a) Contour plot of the $2 \mathrm{D}^{77} \mathrm{Se}$ MATPASS/CPMG spectrum for the LGGS/Se glass of composition $40 \mathrm{Li}_{2} \mathrm{~S}-10 \mathrm{Ga}_{2} \mathrm{Se}_{3}-50 \mathrm{GeSe}_{2}$ with the total isotropic projection (top) and the two anisotropic projections (right) along the dashed lines corresponding to BSe and NBSe environments. (b) The experimental (black line) and simulated (dashed red line) isotropic projection of the MATPASS/CPMG spectrum. Simulation components corresponding to Ge-Se$\mathrm{Ge}(\mathrm{BSe})$ and Ge-Se-Li (NBSe) sites are shown in green and pink, respectively. (c) The experimental (black solid lines) and simulated (red dotted lines) CSA sideband patterns taken at the isotropic chemical shifts of the BSe and NBSe environments.

Figure 5. ${ }^{77}$ Se MAS NMR spectra for representative LGGS/Se glasses with R 1 (left) and R<1 (right). Experimental and simulated line shapes are shown with solid black and dashed red lines, respectively. Individual Gaussian simulation components for Ge-Se-Ge and Ge-Se-Li 
environments in R>1 glasses are shown in green and pink, respectively. Those for Ge-Se-Ge and Ge-Se-Ge-Ge environments in $\mathrm{R}<1$ glasses are shown in green and blue, respectively. Inset shows the chemical shift dependence of the Ge-Se-Ge environment with sulfur content. Glass composition is denoted alongside each spectrum using the same convention as in Fig. 2.

Figure 6. The experimental (solid line) and simulated (dashed line) ${ }^{71}$ Ga QMAT NMR spectra of representative LGGS/Se glasses with $\mathrm{R}<1$ and $\mathrm{R}>1$. Glass composition is denoted alongside each spectrum using the same convention as in Fig. 2. Each spectrum is simulated with a single component using a Czjzek model of distribution for $\mathrm{C}_{\mathrm{q}}$. 


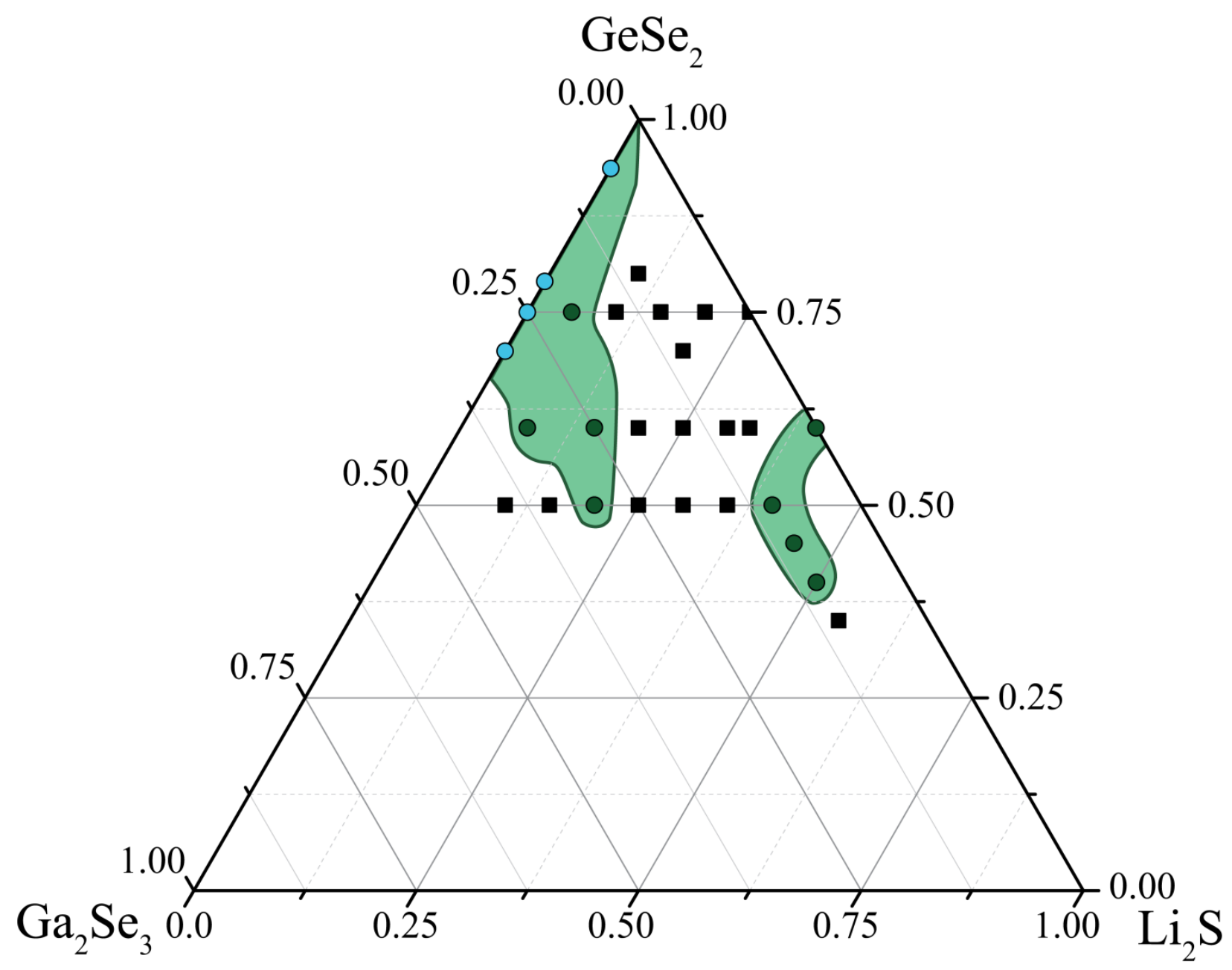

Fig. 1 

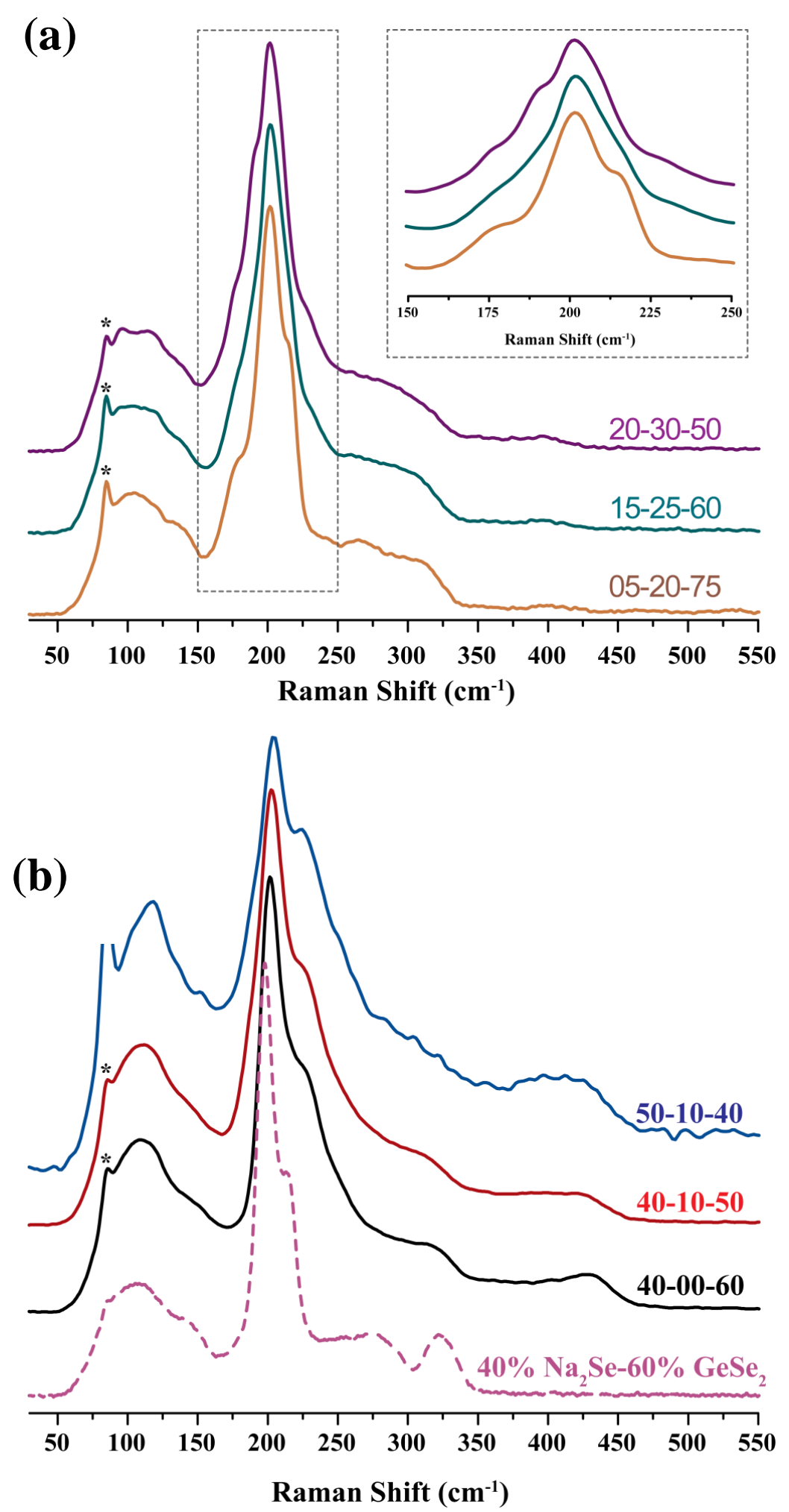

Fig. 2 


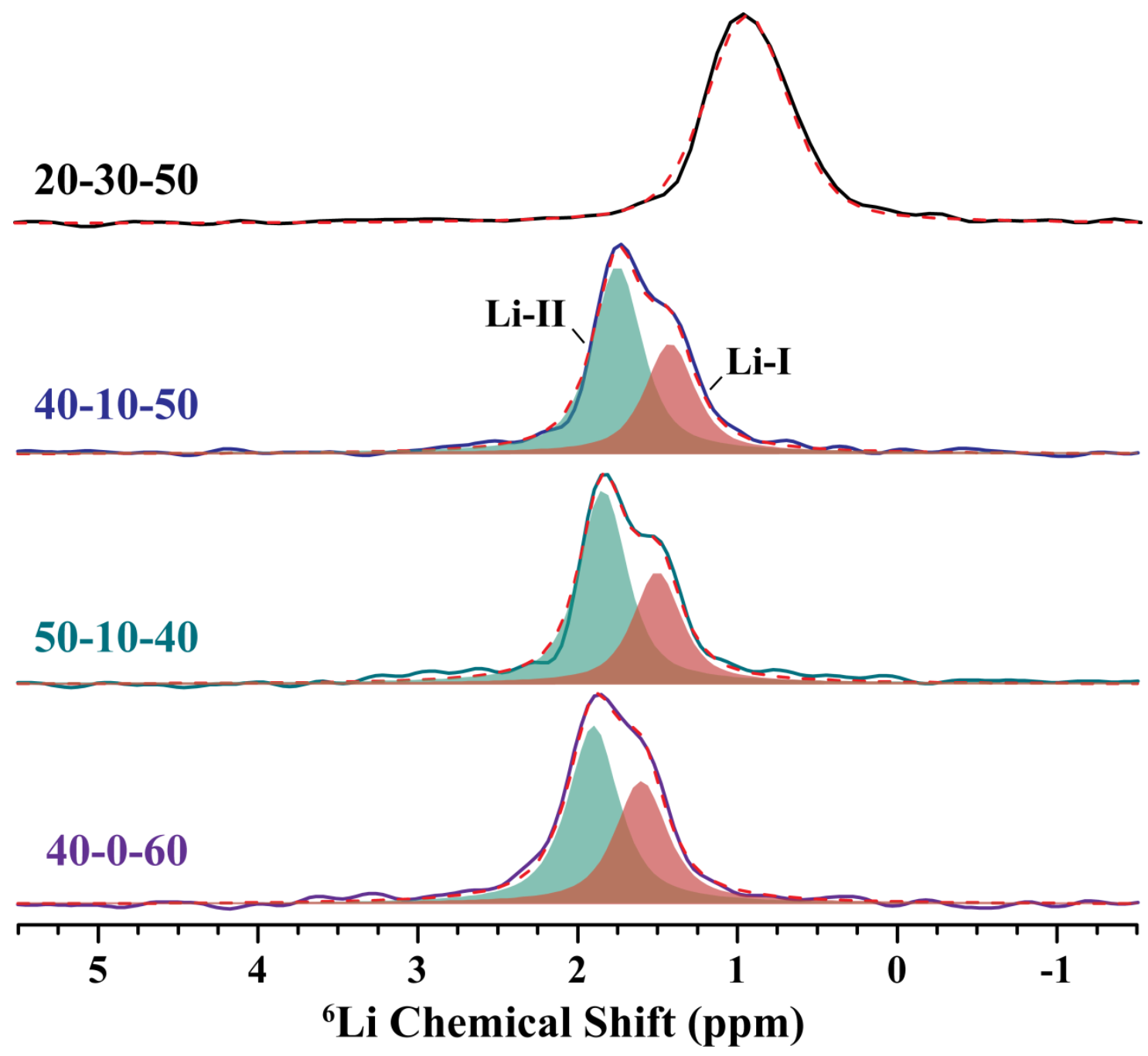

Fig. 3 
(a)

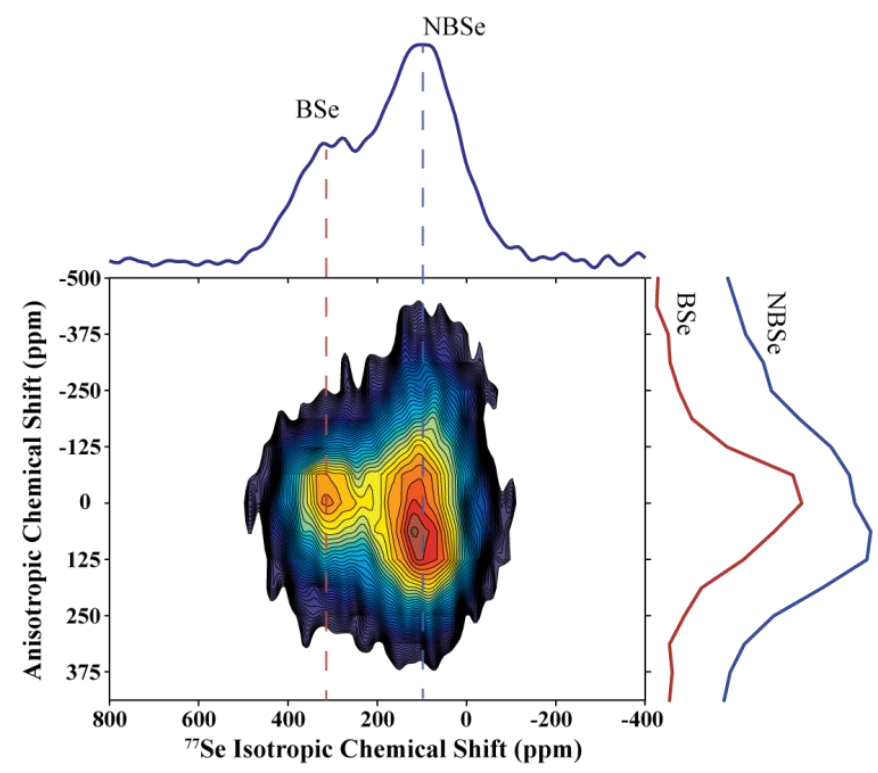

(b)

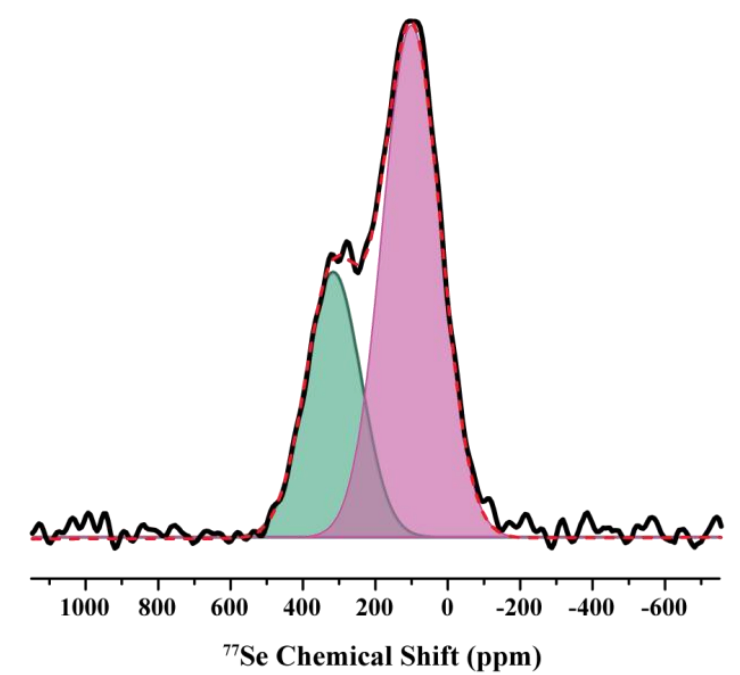

(c)

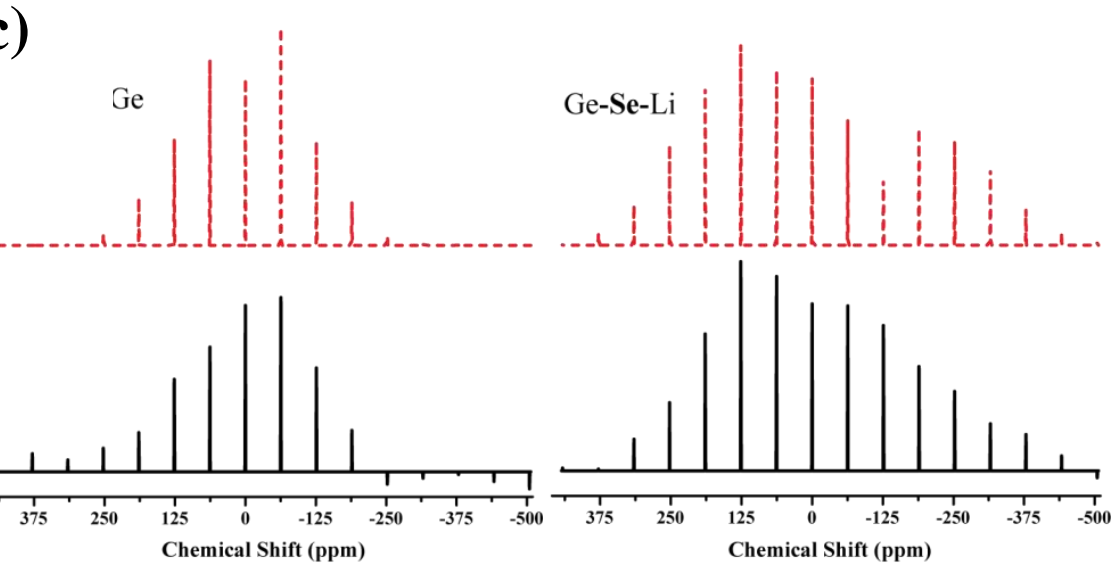

Fig. 4 


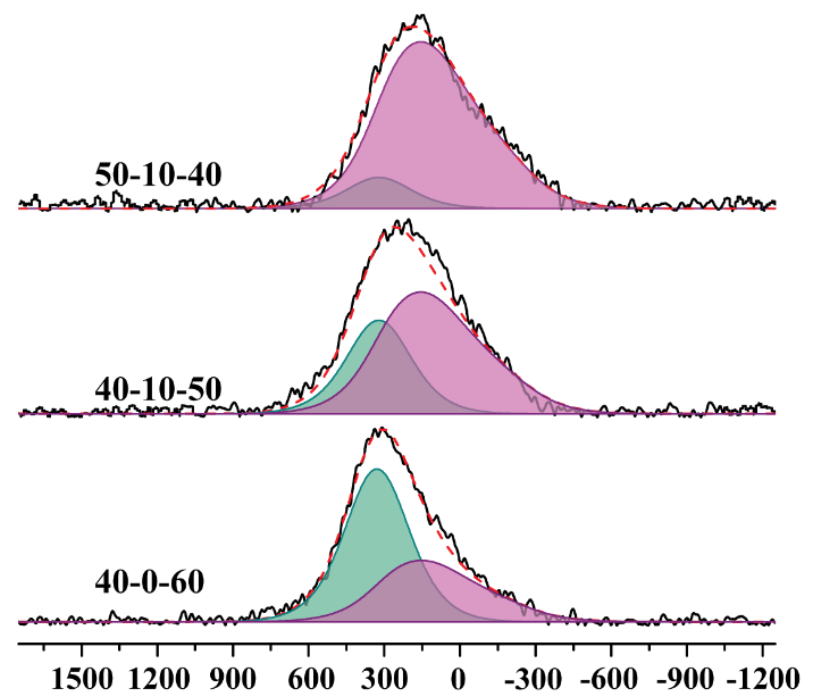

${ }^{77}$ Se Chemical Shift (ppm)

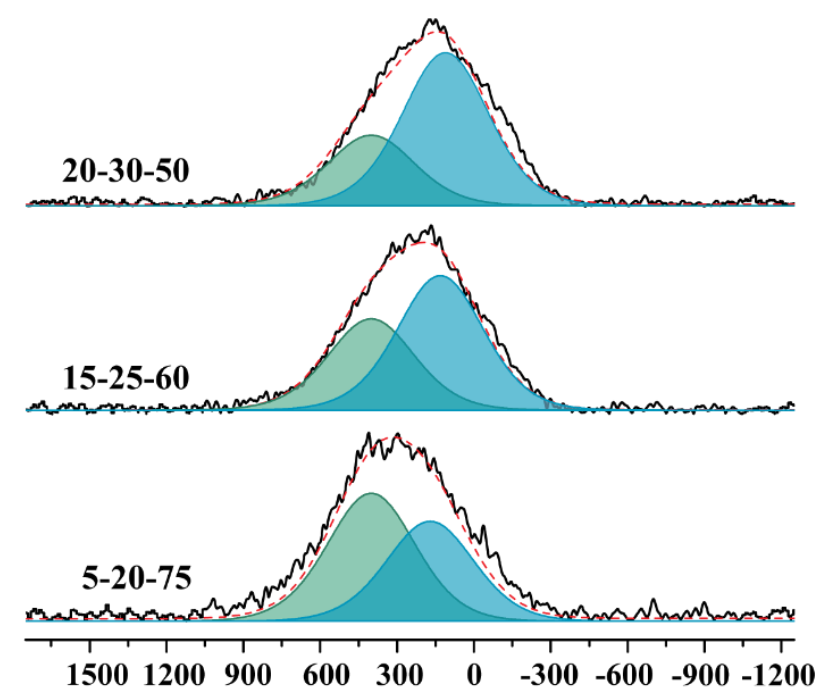

${ }^{77}$ Se Chemical Shift (ppm)

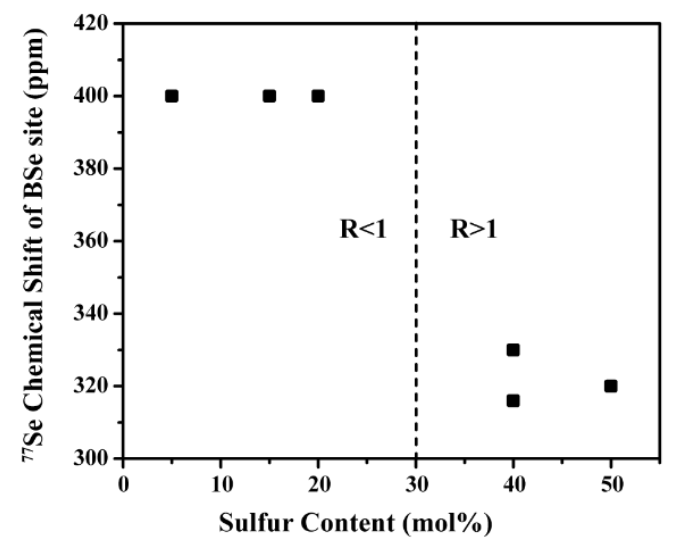

Fig. 5 


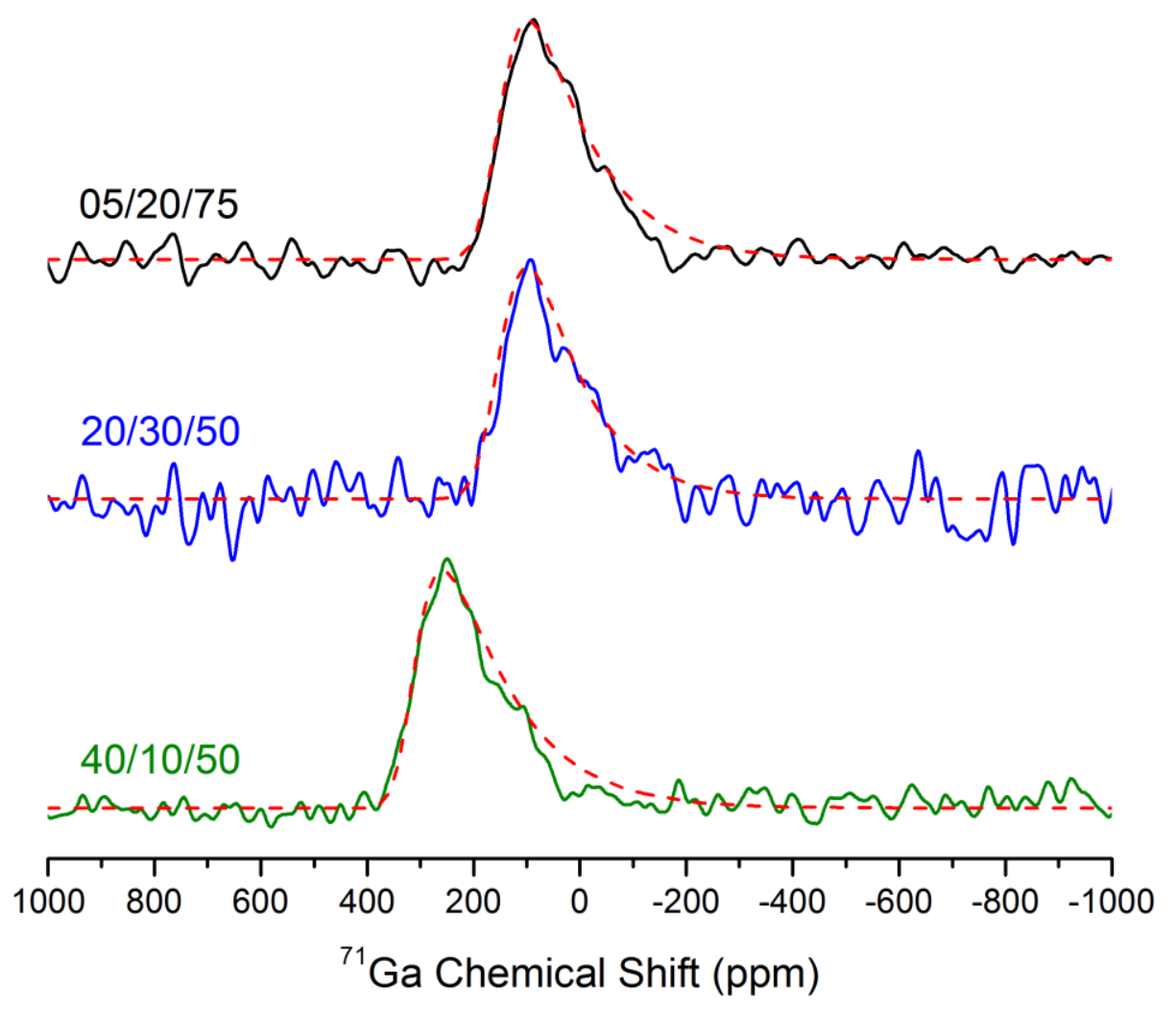

Fig.6 